
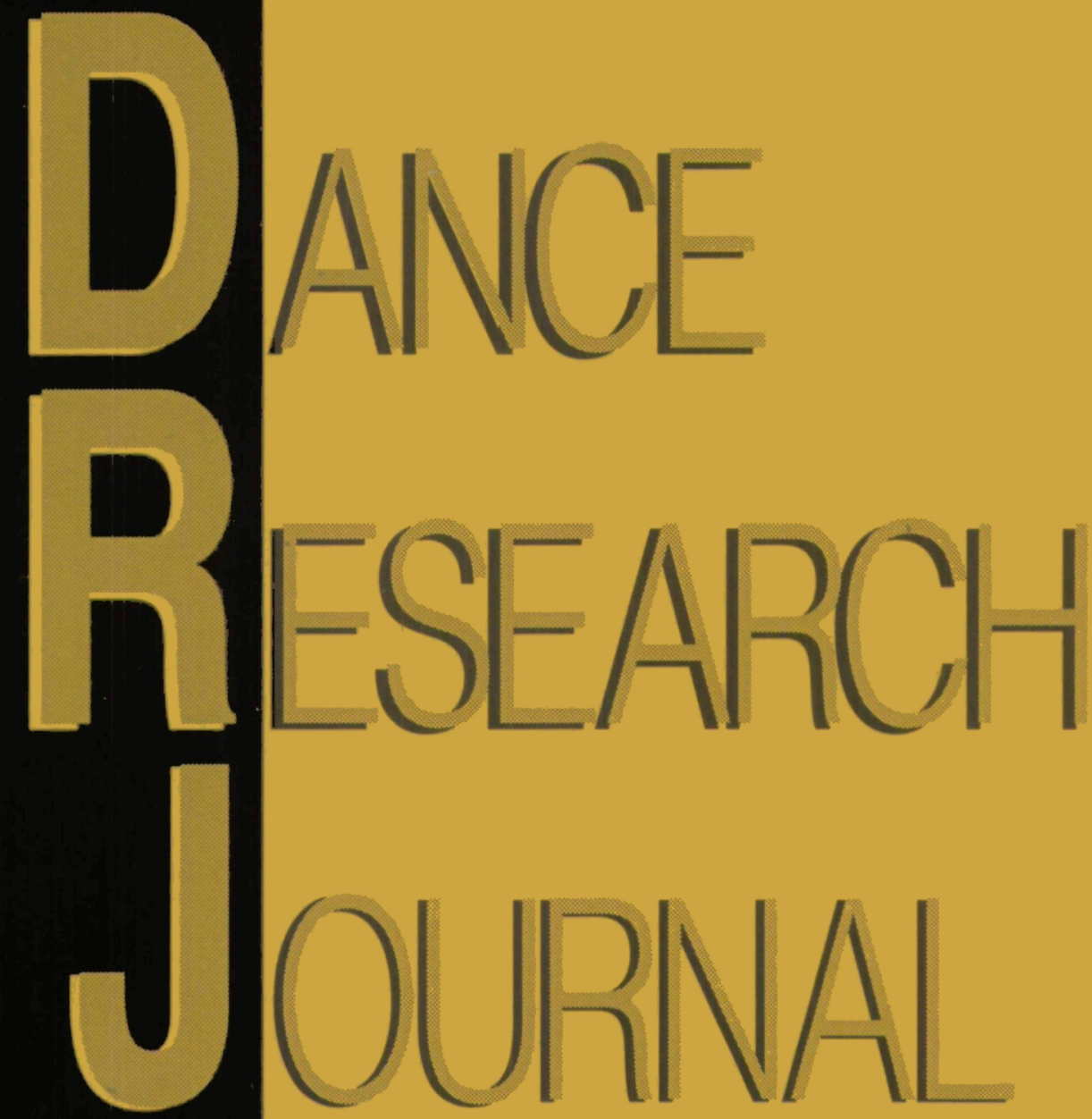

Congress on Research in Dance

ISSN 01497677

31/2 FALL 1999

$\$ 15.00$ 
Dance Research Journal, published twice yearly by the Congress on Research in Dance (CORD), carries scholarly articles, book reviews, a list of books and journals received, and reports of scholarly conferences, archives, and other projects of interest to the field. Contributions for publication consideration are open to both members and nonmembers of CORD, and will be accepted at any time.

Views expressed in $D R J$ are the authors', and not necessarily those of the editors, CORD, or CORD officers.

Editor (through 1999)-Dr. Lynn Matluck Brooks, Dance Program, Franklin \& Marshall College, PO Box 3003, Lancaster, PA 17604-3003 U.S.A.; tel: (717) 291-4204; fax: (717) 291-3969; e-mail: I_brooks@acad.fandm.edu.

Editor-designate (1999); Editor (starting in 2000)-Dr. Julie Malnig, New York University, Gallatin School of Individualized Study, 715 Broadway, New York, NY 10003-6806 U.S.A.; tel: (212) 998-7311; fax: (212) 995-4509; e-mail: julie.malnig@nyu.edu.

Reviews Editor-Lori Salem, The Writing Center, Temple University 265-19, Weiss Hall-room B-19, Philadelphia, PA 19122 U.S.A.; tel: (215) 204-3848; fax: (215) 204-7083; e-mail: Isalem@nimbus.ocis.temple.edu.

Dance Resarch Journal is edited and produced at Franklin \& Marshall College. Membership/subscription information and orders for current or back publications should be directed to CORD, Dept. of Dance, State University of New York. College at Brockport, Brockport, NY 14420 U.S.A.; Tel. (716) 395-2590.

\section{Guide for Contributors}

Articles: Manuscripts should be submitted in triplicate to the $D R J$ Editor. $D R J$ is a refereed journal, using a blind review process. Article manuscripts must be accompanied by written assurance that they have not been published. submitted, or accepted for publication elsewhere. They will not be returned unless accompanied by return postage.

Manuscripts should contribute original material. They may be research reports, discussions of theory and methods, critical syntheses, or evaluations of the state of knowledge or method in the different disciplines involved in dance research. Articles are evaluated by the Editor and at least two outside readers. The review process is completed as quickly as possible, and every attempt is made to notify authors regarding acceptance within three months. The Editor reserves the right to reject or return for revision any material on the grounds of inappropriate subject matter, quality, or length.

Authors must prepare manuscripts for blind review by putting their name on a separate title page only, and by submitting three clear copies of the manuscript. The entire manuscript, including notes, bibliography, and indented long quotations, should be double spaced. Notes must be numbered consecutively throughout the article and typed on a separate sheet as end notes. Manuscripts, including notes and bibliographies, should follow the Chicago Manual of Style, unless the paper is written in a discipline such as anthropology or biology that follows a different method of footnote style. Illustrative materials, such as tables, maps. and graphic notation, should be done in black ink and should be camera-ready copy. Photographs should have a glossy finish, and authors must obtain permission to publish them if taken by individuals other than themselves. All manuscripts must be accompanied by an abstract of 50-100 words and biographical information of four-six lines that includes current evidence of expertise in the topic of the article.

Reviews: Book and media reviews are assigned by the Reviews Editor, but individuals wishing to review a particular book may submit an inquiry to the Reviews Editor. Reviews in the current issue are the best guide to correct format. The heading should include name of author(s) or editor(s), book title (italicized), place of publication, name of publisher, year of publication, number of pages, cloth or paperbound, and price. Reviews should be scholarly in orientation, and approximately $1200-1500$ words in length. A parallel format should be used for film and other material.

Reports: Reports are assigned by the Editor, but individuals wishing to submit a report on a particular conference, activity or country are encouraged to submit an inquiry to the Editor. Reports should include what, where, when, who, and how, and should specify the relevance of the activity to dance research. Related literature should be cited, if relevant.

Final Manuscript Approval: Authors of articles will be consulted before finalization of editorial decisions. Page proofs will be sent during the printing process and should be examined by authors and returned within the specified time.

Copyright: $D R J$ publishes previously unpublished original research. CORD copyrights each issue of the journal as a collective work; individual authors retain rights to their individual works.

Authors of individual works published in CORD have the right to republish their own work in whole or in part, and in identical or modified form. As the original publisher, CORD requests a letter to the Chair of the CORD Editorial Board notifying of any republication. All republications, in whatever form, must be credited with one of the following statements:

This article was originally published in Dance Research Journal, Vol. (number), No. (number), (date).

or

An earlier version of this article appeared in Dance Research Journal, Vol. (number), No (number), (date).

Complimentary Copies: Contributors of major articles will receive three complimentary copies of the issue in which their article was published; authors of reviews and reports will receive two complimentary copies. 


\section{DANGE RESEABCH JOURNAL}

Congress on Research in Dance • 30/2 Fall 1998

\section{CONTENTS}

\section{From the Editor}

\section{Dialogues}

I. Thoughts on "A Warm-up" Joann W. Kealiinohomoku

II. Beardsley, Expression and Dance: A Reply to Gregory Scott Sally Banes and Noël Carroll

\section{Articles}

"All the dances have a meaning to that apparition": Felt knowledge and the Danzantes of Tortugas, New Mexico Deidre Sklar

Athena Meets Venus: Visions of Women in Social Dance in the Teens and Early 1920s

\section{Julie Malnig}

Finnish Dancers' Attitudes Toward Folk, Competitive Ballroom, Ballet, and Modern Dance

Pipsa Nieminen and Väinö Varstala

Somatic Authority and the Myth of the Ideal Body in Dance Education Jill Green

\section{Reviews}

Toepfer. EMPIRE OF ECSTASY: NUDITY AND MOVEMENT

IN GERMAN BODY CULTURE 1910-1935

Marion Kant

Shapiro, ed. DANCE, POWER AND DIFFERENCE: CRITICAL AND FEMINIST PERSPECTIVES ON DANCE EDUCATION Madeleine Lord

Wiley. THE LIFE AND BALLETS OF LEV IVANOV: CHOREOGRAPHER OF THE NUTCRACKER AND SWAN LAKE Jennifer Fisher 
Bird and Greenberg. BIRD'S EYE VIEW: DANCING WITH MARTHA

GRAHAM AND ON BROADWAY

Shelley C. Berg

Banes. DANCING WOMEN: FEMALE BODIES ON STAGE

I. Julie Van Camp

II. Janice Ross

III. Peg Zeglin Brand

IV. Sally Banes

\section{Books Received}

\section{Report}

Congress on Research in Dance Keynote Panel at 2000 Feet: A Celebration of World Dance

Linda Haviland

\section{Research in Dance: Worldwide}

Dance Education and Dance Research in Finland

Pipsa Nieminen

copyright $(\mathcal{C} 1999$ by the Congress on Research in Dance

all rights reserved

ISSN: 01497677

Library of Congress Catalog Card No. 76-12179 